\title{
THERMAL-NEUTRON CAPTURE GAMMA RAYS FROM NATURAL CALCIUM
}

\author{
H. GRUPPELAAR and P. SPILLING \\ Fysisch Laboratorium der Rijksuniversiteit, Utrecht, Nederland
}

Received 1 June 1967

\begin{abstract}
Gamma rays from thermal-neutron capture in natural $\mathrm{Ca}$ and enriched ${ }^{40} \mathrm{Ca}$ were investigated with a $5 \mathrm{~cm}^{3} \mathrm{Ge}(\mathrm{Li})$ detector. Many low-energy $\gamma$-lines have been found. More than $90 \%$ of the $\gamma$-rays result from capture in ${ }^{40} \mathrm{Ca}$ and about $5 \%$ from capture in ${ }^{44} \mathrm{Ca}$. From the data a decay scheme of ${ }^{41} \mathrm{Ca}$ and a partial decay scheme of ${ }^{45} \mathrm{Ca}$ were constructed. The $Q$-values for the reactions ${ }^{40} \mathrm{Ca}(\mathrm{n}, \gamma)^{41} \mathrm{Ca}$ and ${ }^{44} \mathrm{Ca}(\mathrm{n}, \gamma)^{45} \mathrm{Ca}$ were determined as $Q=8363.4 \pm 1.0$ and $7418.1 \pm 3.0 \mathrm{keV}$, respectively.

In ${ }^{41} \mathrm{Ca}$, it is found that hole states preferentially decay to hole states, and single-particle states to single-particle states.
\end{abstract} deduced levels, branching. Enriched ${ }^{40} \mathrm{Ca}$ target, $\mathrm{Ge}(\mathrm{Li})$ detector.

\section{Introduction}

The $\gamma$-rays from thermal-neutron capture in natural calcium have been studied with a magnetic pair spectrometer ${ }^{1}$ ) in 1952 and with a magnetic Compton spectrometer ${ }^{2}$ ) in 1956. Altogether $22 \gamma$-lines have been found and a decay scheme of ${ }^{41} \mathrm{Ca}$ was proposed ${ }^{3,4}$ ). Measurements with $\mathrm{NaI}$ crystals are reported in refs. ${ }^{5-7}$ ). These experiments yield a few additional lines and the spins of several levels in ${ }^{41} \mathrm{Ca}$. It was clear that most of the $\gamma$-rays result from capture in ${ }^{40} \mathrm{Ca}$, but there was no agreement with the values of the thermal-neutron cross sections of the various calcium isotopes ${ }^{8}$ ). The most recent values for these cross sections ${ }^{9}$ ), listed in table 1 , however, predict that about $90 \%$ of the primary $\gamma$-rays must originate from capture in ${ }^{40} \mathrm{Ca}$ and about $1 \%, 2 \%$, and $5 \%$ from ${ }^{42} \mathrm{Ca},{ }^{43} \mathrm{Ca}$ and ${ }^{44} \mathrm{Ca}$, respectively.

Recently, the ${ }^{43} \mathrm{Ca}(\mathrm{n}, \gamma)^{44} \mathrm{Ca}$ reaction has been studied by Cranston et al. $\left.{ }^{10}\right)$ with enriched ${ }^{43} \mathrm{Ca}$ and a $\mathrm{Ge}(\mathrm{Li})$ spectrometer. More than $40 \gamma$-rays were observed. Many $\gamma$-lines from the ${ }^{44} \mathrm{Ca}(\mathrm{n}, \gamma){ }^{45} \mathrm{Ca}$ reaction were observed with $\mathrm{NaI}$ crystals by Raboy and Trail ${ }^{11}$ ).

In the present investigation a $\mathrm{Ge}(\mathrm{Li})$ detector was used to study the $\gamma$-rays from neutron capture in natural calcium. Special attention has been given to the poorly known low-energy $\gamma$-rays. 


\section{Experimental arrangement}

A $5 \mathrm{~cm}^{3} \mathrm{RCA} \mathrm{GeL(i)} \mathrm{detector} \mathrm{was} \mathrm{used} \mathrm{to} \mathrm{measure} \mathrm{the} \mathrm{thermal-neutron} \mathrm{capture}$ $\gamma$-rays from a target, placed in a radial beam emerging from the Dutch High Flux reactor with a thermal neutron flux of about $10^{7} \mathrm{~cm}^{-2} \cdot \mathrm{s}^{-1}$. As targets, $3 \mathrm{~g} \mathrm{CaO}$ and $2.5 \mathrm{~g}{ }^{40} \mathrm{CaO}$ (enrichment $99.97 \%$ ) were used. The enriched sample was on loan from the Electromagnetic Separation Group at Harwell.

With the natural target three spectra were measured, covering energies from 0-2.4, 0-3 and 3-7 MeV. Both with the enriched and the natural target a spectrum in the 0-7 MeV energy region was measured. In each energy region background measurements were also performed. The energy resolution of the detector is $5 \mathrm{keV}$ at $1 \mathrm{MeV}$ and $12 \mathrm{keV}$ at $7 \mathrm{MeV}$.

The electronic equipment is briefly described in ref. ${ }^{12}$ ). All spectra were analysed with a 2048 channel pulse-height analyser.

\section{Analysis of measurements}

The energy calibration curve for each spectrum was obtained with a least-squares procedure, described in ref. ${ }^{12}$ ). A precision pulse generator was used to find the response function of the system. As internal calibration lines, the annihilation radiation and the pair and full-energy peaks of the $2224.5 \pm 0.2 \mathrm{keV}\left(\right.$ ref. $\left.\left.{ }^{13}\right)\right) \gamma$-ray from the ${ }^{1} \mathrm{H}(\mathrm{n}, \gamma)^{2} \mathrm{H}$ reaction were used. Calcium oxyde is very hygroscopic and provides strong hydrogen peaks.

The efficiency curves for the full-energy, single-escape and pair peaks were determined with sources of known intensities and with $\gamma$-rays from the reactions ${ }^{14}$ ) ${ }^{35} \mathrm{Cl}(\mathrm{n}, \gamma){ }^{36} \mathrm{Cl}$ and ${ }^{32} \mathrm{~S}(\mathrm{n}, \gamma){ }^{33} \mathrm{~S}$. The intensities of the $\gamma$-rays from these two reactions have been determined with a $12.7 \times 12.7 \mathrm{~cm} \mathrm{NaI}$ crystal. For an intense $\gamma$-line the error in the intensity is about $15 \%$, due to uncertainties in the efficiency curves.

\section{Results}

In fig. 1, spectra for $E_{\gamma}=0.1-6.5 \mathrm{MeV}$ and $E_{\gamma}=0.3-2.8 \mathrm{MeV}$ are shown. The $\gamma$ spectrum of the ${ }^{40} \mathrm{Ca}(\mathrm{n}, \gamma){ }^{41} \mathrm{Ca}$ reaction, measured with the enriched ${ }^{40} \mathrm{CaO}$ target, is only shown in places where peaks from the reactions ${ }^{42} \mathrm{Ca}(\mathrm{n}, \gamma){ }^{43} \mathrm{Ca},{ }^{43} \mathrm{Ca}(\mathrm{n}, \gamma)$ ${ }^{44} \mathrm{Ca}$ or ${ }^{44} \mathrm{Ca}(\mathrm{n}, \gamma){ }^{45} \mathrm{Ca}$ are visible. The peaks are labelled with unprimed, primed and double-primed energies in $\mathrm{keV}$, indicating full-energy, single- and double-escape peaks, respectively. Background peaks are labelled with the symbol "Bgr" or with the symbol of the corresponding final nucleus, if the contaminant could be identified.

In table 2 the recoil-corrected energies of $\gamma$-rays from the ${ }^{40} \mathrm{Ca}(\mathrm{n}, \gamma)^{41} \mathrm{Ca}$ reaction are given. The $\gamma$-lines of other calcium isotopes are listed in table 5. Mostly, the given value is the weighted mean of the energies corresponding to the full-energy, singleand double-escape peaks in all measured spectra. 


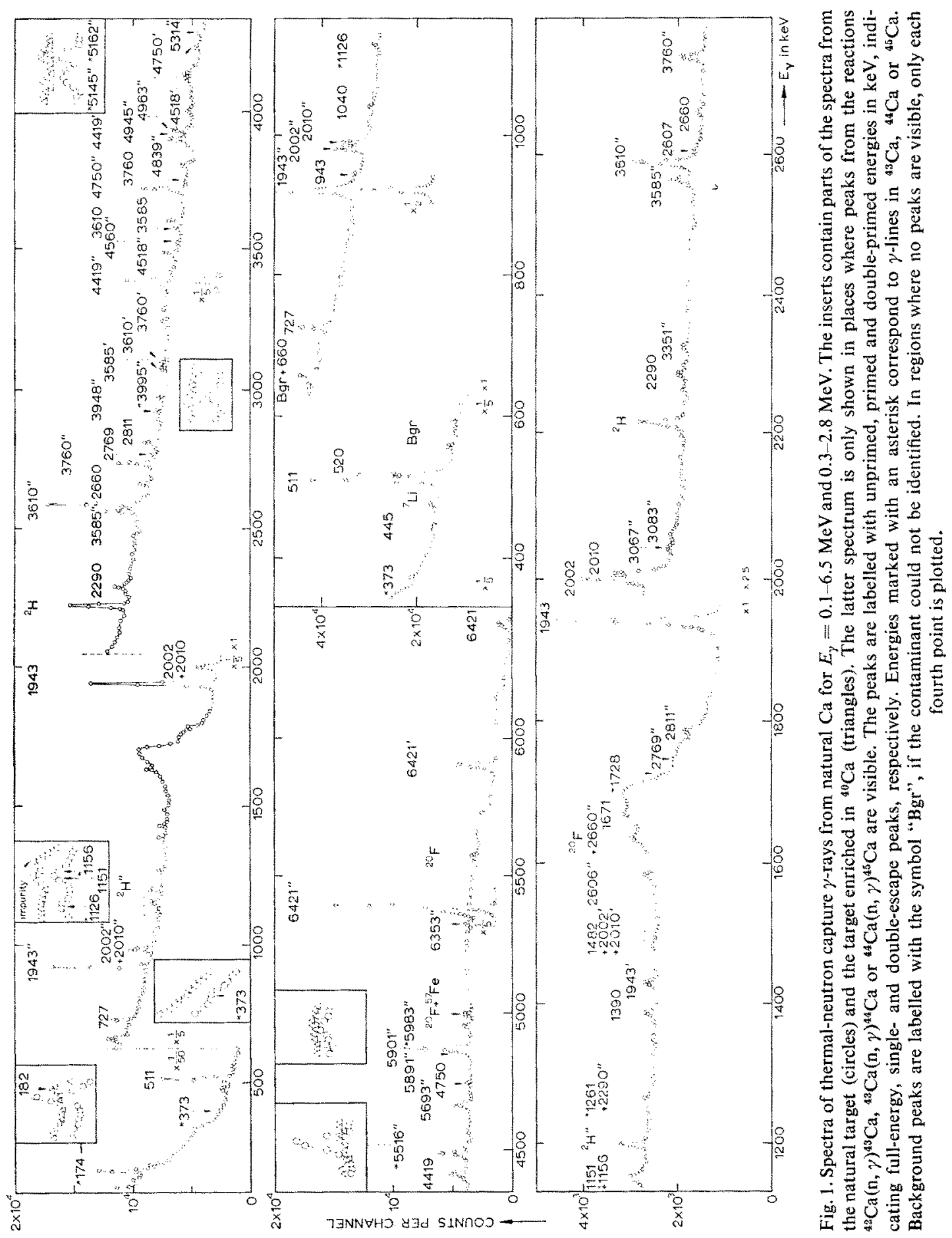


The intensities are normalized such that the sum of the intensities of the 1943 and $2010 \mathrm{keV} \gamma$-lines in ${ }^{41} \mathrm{Ca}$ is 100 . These $\gamma$-lines are de-exciting the first and second excited states of ${ }^{41} \mathrm{Ca}$, respectively. From the present work it was found that no other levels directly decay to the ground state. Recently ${ }^{15}$ ), it has been shown that less than $1 \%$ of the decay of the third excited state directly goes to the ground state. Often, the sum of the intensities of the primary $\gamma$-rays is normalized to 100 . However, this sum may have a large error, because first, there are many primary $\gamma$-rays and second, weak primary $\gamma$-lines may be overlooked.

No statistically significant peaks in natural calcium were found corresponding to $\gamma$-lines with energies above $6.42 \mathrm{MeV}$. Most of the observed new lines have energies

TABLE 1

Thermal-neutron capture cross sections (in b) for the stable calcium isotopes

\begin{tabular}{ccc}
\hline Isotope & Hughes and Schwartz $\left.{ }^{8}\right)$ & Cranston et al. ${ }^{9}$ ) \\
\hline${ }^{40} \mathrm{Ca}(96.97 \%)$ & $0.22 \pm 0.04$ & \\
${ }^{42} \mathrm{Ca}(0.64 \%)$ & $42 \pm 3$ & $0.70 \pm 0.16$ \\
${ }^{43} \mathrm{Ca}(0.145 \%)$ & $0.67 \pm 0.07$ & $6.2 \pm 1.1$ \\
${ }^{44} \mathrm{Ca}(2.06 \%)$ & $0.25 \pm 0.10$ & $1.1 \pm 0.2$ \\
${ }^{46} \mathrm{Ca}(0.003 \%)$ & $1.1 \pm 0.1$ & \\
${ }^{48} \mathrm{Ca}(0.185 \%)$ & $0.44 \pm 0.02$ & $0.41 \pm 0.12$ \\
$\mathrm{Ca}$ (natural) & & \\
\hline
\end{tabular}

below $3.5 \mathrm{MeV}$. Several doublets are resolved, for instance the 2001.8 and $2010.1 \mathrm{keV}$ doublet. Peaks on the Compton edge of the $1943 \mathrm{keV}$ line are uncertain. Yet, it is improbable that a strong $1.79 \mathrm{MeV} \gamma$-line, reported in refs. ${ }^{2,7}$ ), would exist, because no double-escape peak of such a line is visible in fig. 1. Other $\gamma$-lines, which are not observed here, were reported with energies of $1.884 \mathrm{MeV}$ (ref. ${ }^{2}$ )) and $2.252 \mathrm{MeV}$ $\left(\right.$ ref. $\left.{ }^{7}\right)$ ).

Only a few $\gamma$-lines from thermal-neutron capture in other isotopes than ${ }^{40} \mathrm{Ca}$ are visible. Most of them are weak or obscured by other peaks.

\section{Neutron capture in ${ }^{40} \mathrm{Ca}$}

The decay scheme of ${ }^{41} \mathrm{Ca}$ was constructed with the aid of a computer program, which selected cascades between the capturing state and the ground state. Such a cascade is accepted if the sum of the energies equals the $Q$-value, determined from the $\mathrm{C} \rightarrow 1943 \rightarrow 0 \mathrm{keV}$ cascade (C denotes the capturing state) to within $3 \mathrm{keV}$, and if the intermediate energy levels correspond to those found from the $(d, p)$ work $\left.{ }^{16}\right)$. The decay scheme is shown in fig. 2 .

The excitation energies, listed in table 3 , are calculated from a least-squares program, which gives the most probable solution of a system of linear equations. In this case 19 (correlated) energy relations exist, see table 4 . The (normalized) $x^{2}$ value was 
TABLE 2

Gamma rays observed in the ${ }^{40} \mathrm{Ca}(\mathrm{n}, \gamma)^{41} \mathrm{Ca}$ reaction

\begin{tabular}{|c|c|c|}
\hline $\begin{array}{l}\left.E_{\gamma}^{\mathrm{a}}\right) \\
(\mathrm{keV})\end{array}$ & $\begin{array}{c}\text { Intensity } \\
\text { (number of } \gamma \text {-rays } \\
\text { per } 100 \text { captures }{ }^{b} \text { )) }\end{array}$ & $\begin{array}{l}\left.\text { Interpretation }{ }^{c}\right) \\
\left(E_{\mathrm{x}} \text { in keV }\right)\end{array}$ \\
\hline \multicolumn{3}{|l|}{182} \\
\hline $444.5 \pm 0.4$ & 0.5 & $3845 \rightarrow 3400$ \\
\hline $519.7 \pm 0.3$ & 13.4 & $2463 \rightarrow 1943$ \\
\hline $660.2 \div 0.6$ & 0.8 & $2670 \rightarrow 2010$ \\
\hline $727.3 \pm 0.4$ & 2.1 & $2670 \rightarrow 1943$ \\
\hline $943.0 \pm 1.0$ & 0.5 & $3614 \rightarrow 2670$ \\
\hline $1040.1 \pm 1.5$ & 0.3 & $3050 \rightarrow 2010$ \\
\hline $1150.9 \pm 1.5$ & 1.1 & $3614 \rightarrow 2463$ \\
\hline $1389.6 \pm 1.0$ & 2.2 & $3400 \rightarrow 2010$ \\
\hline $1482.1 \pm 1.5$ & 1.3 & $3945 \rightarrow 2463$ \\
\hline $1671.2 \pm 1.0$ & 1.3 & $3614 \rightarrow 1943$ \\
\hline $1942.7 \pm 0.3$ & 88.5 & $1943 \rightarrow 0$ \\
\hline $2001.8 \pm 0.4$ & 18.9 & $3945 \rightarrow 1943$ \\
\hline $2010.1 \pm 0.5$ & 11.5 & $2010 \rightarrow \quad 0$ \\
\hline $2290.3 \pm 0.8$ & 1.6 & $4753 \rightarrow 2463$ \\
\hline $2606.6 \pm 0.5$ & 1.6 & \\
\hline $2660.4 \pm 2.0$ & 1.3 & $\begin{aligned} 4603 & \rightarrow 1943 \\
(\mathrm{C} & \rightarrow 5703)\end{aligned}$ \\
\hline $2768.9 \div 2.0$ & 2.8 & $4778 \rightarrow 2010$ \\
\hline $2811.2 \pm 1.5$ & 3.8 & $4753 \rightarrow 1943$ \\
\hline $3067.4 \pm 2.0$ & 0.7 & $5012 \rightarrow 1943$ \\
\hline $3083.1 \pm 2.0$ & 0.7 & \\
\hline $3351.1 \pm 1.5$ & 0.4 & $C \rightarrow 5012$ \\
\hline $3585.4 \pm 0.6$ & 1.6 & $C \rightarrow 4778$ \\
\hline $3610.3 \pm 0.4$ & 6.0 & $\mathrm{C} \rightarrow 4753$ \\
\hline $3760.0 \leq 0.8$ & 3.1 & $\begin{aligned} C & \rightarrow 4603 \\
(5703 & \rightarrow 1943)\end{aligned}$ \\
\hline $3947.5=3.0$ & 0.4 & \\
\hline $4419.4+1.0$ & 17.1 & $\mathrm{C} \rightarrow 3945$ \\
\hline $4518.0-3.0$ & 0.7 & $C \rightarrow 3845$ \\
\hline $4560.0 \div 3.0$ & 0.1 & \\
\hline $4749.6=1.5$ & 2.6 & $C \rightarrow 3614$ \\
\hline $4839.0 \pm 3.0$ & 0.5 & $(\mathrm{C} \rightarrow 3525)$ \\
\hline $4944.7 \pm 3.0$ & 0.8 & \\
\hline $4962.7 \pm 2.0$ & 1.8 & $C \rightarrow 3400$ \\
\hline $5314.1 \div 3.0$ & 0.3 & $C \rightarrow 3050$ \\
\hline $5692.9 \div 2.0$ & 1.1 & $C \rightarrow 2670$ \\
\hline $5900.7 \pm 1.0$ & 7.0 & $C \rightarrow 2463$ \\
\hline $6352.5 \pm 3.0$ & 0.2 & $C \rightarrow 2010$ \\
\hline $6421.2 \pm 1.0$ & 43.5 & $C \rightarrow 1943$ \\
\hline
\end{tabular}

a) Corrected for recoil losses.

b) The sum of the intensities of the 1943 and $2010 \mathrm{keV} \gamma$-lines is 100 .

c) $\mathbf{C}$ denotes the capturing state.

0.2 , which might indicate that the statistical errors in the energies are about half of the given errors. With this method, accurate determinations of the excitation energies and 


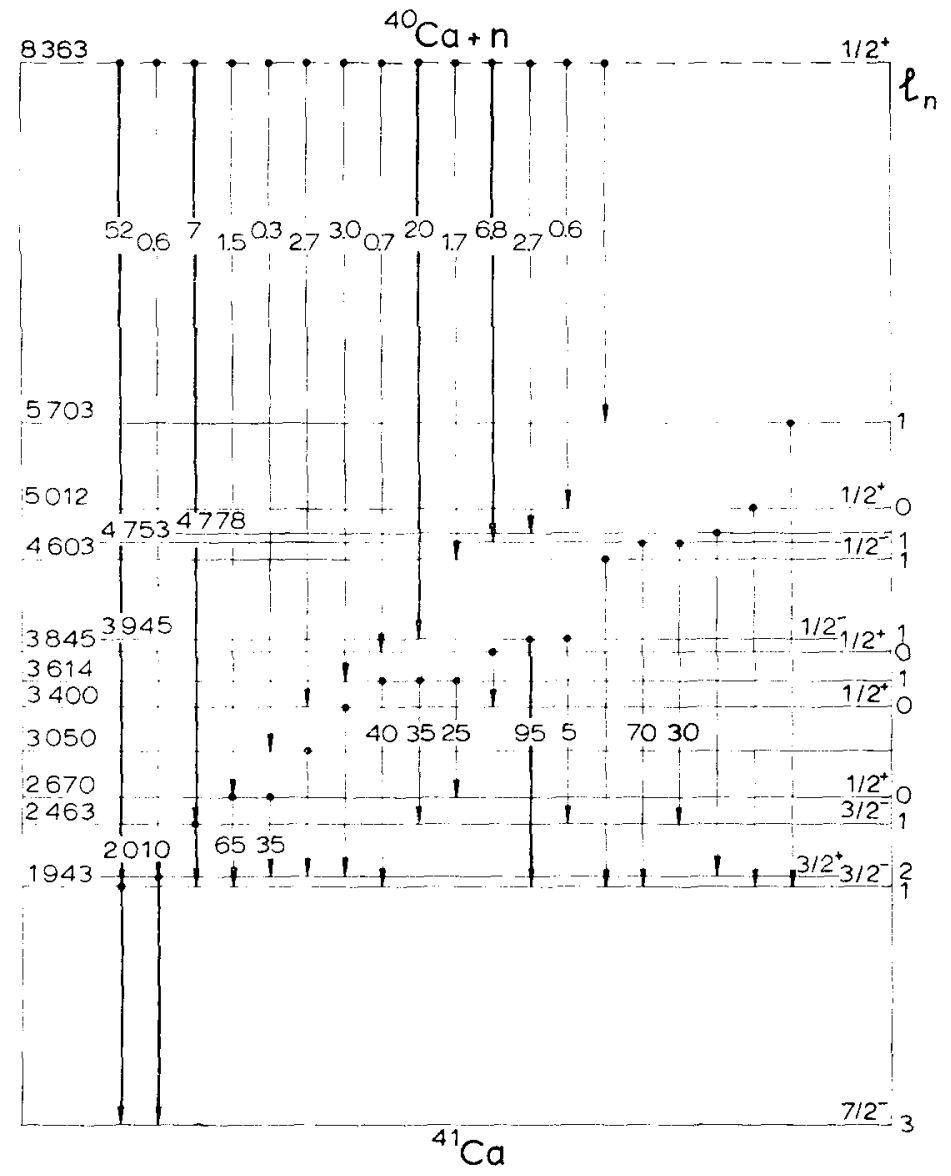

Fig. 2. Decay scheme of ${ }^{41} \mathrm{Ca}$. The intensities of primary $\gamma$-rays are in numbers per 100 captures. For the bound levels the branching ratios are given.

TABLE 3

Excitation energies and intensity balance

\begin{tabular}{|c|c|c|}
\hline$F_{\mathrm{x}}\left({ }^{41} \mathrm{Ca}\right)(\mathrm{keV})$ & Intensity in & Intensity out \\
\hline 0 & $\left.100.0^{a}\right)$ & \\
\hline $1942.7 \pm 0.3$ & 85.0 & 88.51 (100 \\
\hline $2010.1+0.4$ & 6.3 & $11.5\left(100.0^{a}\right)$ \\
\hline $2462.5 \pm 0.4$ & 12.4 & 11.0 \\
\hline $2670.1 \pm 0.4$ & 1.6 & 2.9 \\
\hline $3050.1 \pm 0.6$ & 0.3 & 0.3 \\
\hline $3399.9 \perp 0.8$ & 2.3 & 2.2 \\
\hline $3613.6 \pm 0.6$ & 2.6 & 2.9 \\
\hline $3844.5 \pm 0.8$ & 0.7 & 0.5 \\
\hline $3944.5 \pm 0.6$ & 17.1 & 20.2 \\
\hline $4603.4 \pm 0.8$ & 3.1 & 1.3 \\
\hline $4753.1 \subseteq 0.6$ & 6.0 & 5.4 \\
\hline $4778.1 \pm 0.7$ & 1.6 & 2.8 \\
\hline $5011.5 \pm 1.0$ & 0.4 & 0.7 \\
\hline $\left.\mathrm{C}^{\mathrm{b}}\right)$ & & 85.4 \\
\hline
\end{tabular}

a) The normalization is the same as in table 2.

b) $\mathrm{C}$ denotes the capturing state. 
Table 4

Determination of the $Q$ value of the ${ }^{40} \mathrm{Ca}(\mathrm{n}, \gamma)^{41} \mathrm{Ca}$ reaction (all energies in keV)

\begin{tabular}{clrl}
\hline 1. & $1942.7+6421.2$ & $=8363.9 \pm 1.0$ \\
2. & $1942.7+519.7+5900.7$ & $=8363.1 \pm 1.1$ \\
3. & $1942.7+519.7+1150.9+4749.6$ & $=8362.9 \pm 2.2$ \\
4. & $1942.7+519.7+1482.1+4419.4$ & $=8363.9 \pm 1.8$ \\
5. & $1942.7+519.7+2290.3+3610.3$ & $=8363.0 \pm 1.0$ \\
6. & $1942.7+727.3+5692.9$ & $=8362.9 \pm 2.1$ \\
7. & $1942.7+727.3+943.0+4749.6$ & $=8362.6 \pm 1.9$ \\
8. & $1942.7+1671.2+4749.6$ & $=8363.5 \pm 1.8$ \\
9. & $1942.7+2001.8+4419.4$ & $=8363.9 \pm 1.1$ \\
10. & $1942.7+2660.4+3760.0$ & $=8363.1 \pm 2.2$ \\
11. & $1942.7+2811.2+3610.3$ & $=8364.2 \pm 1.6$ \\
12. & $1942.7+3067.4+3351.1$ & $=8361.2 \pm 2.5$ \\
13. & $2010.1+6352.5$ & $=8362.6 \pm 3.0$ \\
14. & $2010.1+660.2+5692.9$ & $=8363.2 \pm 2.2$ \\
15. & $2010.1+660.2+943.0+4749.6$ & $=8362.9 \pm 1.9$ \\
16. & $2010.1+1040.1+5314.1$ & $=8364.3 \pm 3.4$ \\
17. & $2010.1+1389.6+4962.7$ & $=8362.4 \pm 2.3$ \\
18. & $2010.1+1389.6+444.5+4518.0$ & $=8362.2 \pm 3.2$ \\
19. & $2010.1+2768.9+3585.4$ & $=8364.4 \pm 2.3$ \\
From least-squares (see text) & $Q=8363.4 \pm 0.2$
\end{tabular}

a) This value of $Q$ is not the weighted mean of all above mentioned energy sums, because these are correlated.

TABLE 5

Thermal-neutron capture $\gamma$-rays from capture in ${ }^{42} \mathrm{Ca},{ }^{43} \mathrm{Ca}$ and ${ }^{44} \mathrm{Ca}$

\begin{tabular}{|c|c|c|c|}
\hline $\begin{array}{l}\left.E_{\gamma}^{\mathrm{a}}\right) \\
(\mathrm{keV})\end{array}$ & $\begin{array}{c}\text { Relative } \\
\text { intensity }{ }^{b} \text { ) }\end{array}$ & $\begin{array}{c}\text { Final } \\
\text { nucleus }\end{array}$ & $\begin{array}{c}\left.\text { Interpretation }^{\mathbf{c}}\right) \\
\left(E_{\mathbf{x}} \text { in } \mathrm{keV}\right)\end{array}$ \\
\hline $174.4 \pm 0.6$ & $\approx 6.8$ & ${ }^{45} \mathrm{Ca}$ & $174 \rightarrow$ \\
\hline $373.2 \pm 0.5$ & 0.2 & ${ }^{43} \mathrm{Ca}$ & $373 \rightarrow \quad 0$ \\
\hline $1126.3 \pm 1.5$ & 0.6 & ${ }^{44} \mathrm{Ca}$ & $2282 \rightarrow 1156$ \\
\hline $1156.4 \pm 0.5$ & 1.8 & $\left.{ }^{44} \mathrm{Ca}{ }^{d}\right)$ & $1156 \rightarrow \quad 0$ \\
\hline $1261.2 \pm 1.5$ & 0.2 & $\left.{ }^{45} \mathrm{Ca}^{d}\right)$ & $1436 \rightarrow 174$ \\
\hline $1728.0 \pm 5.0$ & $\leqq 0.5$ & $\left.{ }^{45} \mathrm{Ca}{ }^{e}\right)$ & $1903 \rightarrow 174$ \\
\hline $3995.3 \pm 3.0$ & 0.3 & ${ }^{45} \mathrm{Ca}$ & $C \rightarrow 3423$ \\
\hline $5144.5 \pm 5.0$ & 0.2 & & \\
\hline $5161.5 \pm 5.0$ & 0.2 & ${ }^{45} \mathrm{Ca}$ & $C \rightarrow 2257$ \\
\hline $5515.6 \pm 2.0$ & 1.9 & ${ }^{45} \mathrm{Ca}$ & $C \rightarrow 1903$ \\
\hline $5891.2 \pm 5.0$ & & d) & \\
\hline $5982.5 \pm 3.0$ & 0.5 & ${ }^{45} \mathrm{Ca}$ & $C \rightarrow 1436$ \\
\hline
\end{tabular}

a) Corrected for recoil losses.

b) The normalization is the same as in table 2 .

e) $\mathrm{C}$ denotes the capturing state.

d) The interpretation is uncertain, because the peak is obscured by a peak corresponding to a line in ${ }^{41} \mathrm{Ca}$.

e) The interpretation is uncertain, because the peak is situated on the Compton edge of the $1943 \mathrm{keV}$ $\gamma$-line in ${ }^{41} \mathrm{Ca}$. 
the $Q$-value can be made. It also gives a test on the consistency of the decay scheme. The excitation energies from ref. ${ }^{16}$ ) are systematically about $10 \mathrm{keV}$ too high. The $Q$-value has been determined as $Q=8363.4 \mathrm{keV}$ with a statistical error of $0.2 \mathrm{keV}$.

In order to trace a possible systematic error in the neutron separation energy, the $Q$-value was again calculated twice. In the first calculation primary $\gamma$-lines with $E_{\gamma}<4 \mathrm{MeV}$ got a very small weight, in the second calculation the same was done with primary $\gamma$-lines with $E_{\gamma}>4 \mathrm{MeV}$. In the latter calculation only energies below 4 $\mathrm{MeV}$ were used. These energies cannot have big systematic errors because below $4 \mathrm{MeV}$ the calibration curve is based on well known energies. The results are $Q=8363.2 \pm 0.5$ and $Q=8363.3 \pm 0.3 \mathrm{keV}$, respectively. Though no serious systematic errors appear, it seems reasonable to estimate the systematic error in $Q$ as at most $1 \mathrm{keV}$. On the base of this estimate a proportional systematic error has been added to the statistical errors in $E_{\mathrm{x}}$ (table 3). The neutron separation energy, $Q=8363.4 \pm 1.0 \mathrm{keV}$, is in good agreement with the $Q$-value given in the 1964 mass table ${ }^{17}$ ), $Q=8364 \pm 7 \mathrm{keV}$.

TABLE 6

Some coincidence measurements with two Nal crystals ${ }^{\text {a }}$ )

\begin{tabular}{lll}
\hline$E_{\gamma}(\mathrm{MeV})$ & Gate $(\mathrm{MeV})$ & \multicolumn{1}{c}{ Coincident $\gamma$-rays $\left.{ }^{\mathrm{b}}\right)(\mathrm{MeV})$} \\
\hline $1.94,2.00$ & $1.87-2.02$ & all strong lines in ${ }^{41} \mathrm{Ca}$ \\
3.61 & $3.53-3.70$ & $1.94,2.29,2.81$ \\
4.42 & $4.30-4.50$ & $0.52,1.48,1.94,2.00$ \\
4.75 & $4.55-4.80$ & $0.94,1.15,1.67,1.94$ \\
4.96 & $4.82-5.10$ & $1.39,2.00$ \\
5.90 & $5.80-6.05$ & $0.52,1.94$ \\
6.42 & $6.30-6.55$ & 1.94 \\
$>6.42$ & $6.90-9.60$ & 1.14 (double) \\
\hline
\end{tabular}

a) The measurements were performed with the angular-correlation set-up described in ref. ${ }^{24}$ ).

b) Only the strongest $\gamma$-lines are listed.

The intensity sum of $\gamma$-rays feeding a level and that of $\gamma$-rays by which it is de-excited must be in balance. Table 3 shows good agreement for most levels. The sum of the primary $\gamma$-rays is less than 100 . This is partly due to the fact that the feeding intensity of the $2010 \mathrm{keV}$ level is too small. Probably, some weak lines are not observed. Furthermore, a few $\gamma$-lines could not be fitted into the level scheme.

With the least-squares program, mentioned above, all intensities are fitted. The results are shown in the decay scheme. For the bound levels only the branching ratios are given.

In table 6, some coincidence measurements with two $12.7 \times 12.7 \mathrm{~cm} \mathrm{NaI}$ crystals are reported. These measurements agree with the decay scheme of fig. 2 .

The $l_{\mathrm{n}}$ values in fig. 2 are from ref. ${ }^{16}$ ), and the spin assignments of the levels with energies 1943, 2463, 3945 and $4753 \mathrm{keV}$ from refs. ${ }^{5,6,18,19}$ ).

The mean life of the $2010 \mathrm{keV}$ state, obtained from a pulsed beam experiment, is $1.0 \pm 0.1 \mathrm{~ns}\left(\right.$ ref. $\left.^{20}\right)$ ). This excludes a spin $\frac{5}{2}$ for the second excited state of ${ }^{41} \mathrm{Ca}$. These spin assignments are in good agreement with the observed decay. 
The observed primary $\gamma$-rays proceed mainly $\left(>90 \%\right.$ ) to $l_{\mathrm{n}}=1$ levels and all these levels de-excite to the first excited state of ${ }^{41} \mathrm{Ca}$. Most $l_{\mathrm{n}}=0$ levels de-excite to the $2010 \mathrm{keV}$ level. The reason for this may be that the $E_{\mathrm{x}}=2010 \mathrm{keV}$ level $\left(l_{\mathrm{n}}=2\right)$ and some higher $l_{\mathrm{n}}=0$ states have hole configurations. The 2010,2670 and 3400 $\mathrm{keV}$ states are strongly excited in the ${ }^{42} \mathrm{Ca}(\mathrm{t}, \alpha){ }^{41} \mathrm{Ca}$ and ${ }^{42} \mathrm{Ca}(\mathrm{p}, \mathrm{d}){ }^{41} \mathrm{Ca}$ reactions (refs. ${ }^{21,22}$ )), which is an indication for hole configurations of these states. From the decay of ${ }^{41} \mathrm{Ca}$ it should follow that $\gamma$-transitions between two hole states and between two single-particle states are favoured. As a consequence M1 radiation is favoured. This is well known for heavier nuclei.

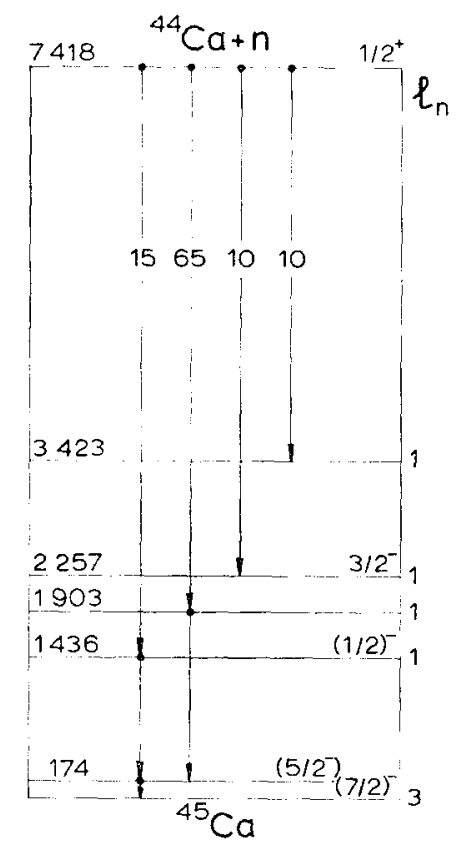

Fig. 3. Partial decay scheme of ${ }^{45} \mathrm{Ca}$. The sum of the intensities of the observed primary $\gamma$-rays is normalized to 100 .

One $l_{\mathrm{n}}=0$ state, with $E_{\mathrm{x}}=5012 \mathrm{keV}$, does not de-excite to the $2010 \mathrm{keV}$ level, but to the $1943 \mathrm{keV}, J=\frac{3}{2}^{-}$, level. This indicates that the $5012 \mathrm{keV}$ state has $3 \mathrm{~s}_{\frac{1}{2}}$ single-particle character, instead of a hole configuration.

In the case of the $\mathrm{C} \rightarrow 4603 \rightarrow 1943 \mathrm{keV}$ cascade a mirror transition is possible with an intermediate level at $5703 \mathrm{keV}\left(l_{\mathrm{n}}=1\right)$. Because the strengths $(2 J+1) S_{\mathrm{n}}$ of the 4603 and $5703 \mathrm{keV}$ levels are 0.216 and 0.133 (ref. ${ }^{16}$ )), respectively, the $\mathrm{C} \rightarrow 4603$ $\rightarrow 1943 \mathrm{keV}$ cascade is more probable.

Most $\gamma$-lines in the decay scheme proposed by Groshev et al. ${ }^{3}$ ), are fitted in the same way as here. However, no transition from the $2463 \mathrm{keV}$ level to the $2010 \mathrm{keV}$ level ${ }^{3}$ ) is observed. Instead, an intense $520 \mathrm{keV} \gamma$-line fits between the two $\frac{3}{2}^{-}$states at 2463 and $1943 \mathrm{keV}$. 


\section{Neutron capture in ${ }^{42} \mathrm{Ca},{ }^{43} \mathrm{Ca}$ and ${ }^{44} \mathrm{Ca}$}

In ${ }^{43} \mathrm{Ca}$, only the ground-state transition from the first excited state is observed. The feeding of this level remains unknown.

Two lines can be fitted into the level scheme of ${ }^{44} \mathrm{Ca}$. In a coincidence measurement (table 6) with a gate above $6.42 \mathrm{MeV}$ these two lines were also observed. Both lines and the feeding of the 1156 and $2282 \mathrm{keV}$ levels are reported in ref. ${ }^{10}$ ).

Seven lines are fitted into the level scheme of ${ }^{45} \mathrm{Ca}$. These lines were also observed with $\mathrm{NaI}$ crystals ${ }^{11}$ ). A partial decay scheme of ${ }^{45} \mathrm{Ca}$ is shown in fig. 3. Most of the spin and $l_{\mathrm{n}}$ values are from ref. ${ }^{4}$ ). The spin of the $2257 \mathrm{keV}$ level was determined by Coté et al. ${ }^{23}$ ). The $Q$-value, determined from the $\mathrm{C} \rightarrow 1436 \rightarrow 174 \rightarrow 0 \mathrm{keV}$ cascade is $7418.1 \pm 3.0 \mathrm{keV}$, and from the $\mathrm{C} \rightarrow 1903 \rightarrow 174 \rightarrow 0 \mathrm{keV}$ cascade $7418.0 \pm 5.0$ $\mathrm{keV}$. These values agree well with the $Q$-value from the 1964 mass table, $Q=7420.3$ $\pm 4.9 \mathrm{keV}$ (ref. $\left.{ }^{17}\right)$ ). The sum of the intensities of the primary $\gamma$-rays is about half the intensity of the $174 \mathrm{keV}$ line. However, the intensity of this line is not very well determined.

Using the thermal-neutron capture cross section for natural $\mathrm{Ca}\left(0.44 \mathrm{~b}\right.$, ref. $\left.\left.{ }^{8}\right)\right)$ and the relative intensities of the observed $\gamma$-lines from the reactions $40,42,43,44 \mathrm{Ca}$ $(\mathrm{n}, \gamma)$, the capture cross sections are determined as $0.43 \mathrm{~b}, 0.1 \mathrm{~b}, 5.1 \mathrm{~b}$ and $1.4 \mathrm{~b}$, respectively. This is in good agreement with the capture cross sections measured by Cranston et al. (table 1).

It is a pleasure to thank Professor P. M. Endt for his interest in this work and his suggestions in the interpretation of the results. R. J. S. Harry and K. Abrahams are acknowledged for the use of their pulse-height analysers. We thank H. F. de Vries and A. M. J. Spits for their help in working out the data.

This investigation was partly supported by the joint program of the "Stichting voor Fundamenteel Onderzoek der Materie" and the "Nederlandse Organisatie voor Zuiver Wetenschappelijk Onderzoek". The hospitality and co-operation of the "Stichting Reactor Centrum Nederland" were highly appreciated.

\section{References}

1) B. B. Kinsey, G. A. Bartholomew and W. H. Walker, Phys. Rev. 85 (1952) 1012

2) B. P. Ad'yasevich, L. V. Groshev, A. M. Demidov and V. N. Lutkenso, Atomn. Energ. (USSR) 1 (1956) 40; J. Nuclear Energy 3 (1956) 258

3) L. V. Groshev, A. M. Demidov and V. N. Lutkenso, Atlas of gamma-ray spectra from radiative capture of thermal neutrons (Pergamon, London, 1959)

4) P. M. Endt and C. van der Leun, Nuclear Physics 34 (1962) 1

5) K. Abrahams and A. Tveter, Congrès International de Physique Nucléaire, Paris, 2-8 juillet 1964 , Vol. II, 420

6) K. Abrahams, W. Ratynski, F. Stecher-Rasmussen and E. Warming, Proc. of the Int. Conf. on the Study of Nuclear Structure with Neutrons, Antwerp (1965) 510

7) R. C. Greenwood and J. H. Reed, IIT Research Institute Report, IITRI-1193-53 (1965) 167

8) D. J. Hughes and R. B. Schwartz, Brookhaven Nat. Lab. Rep., BNL-325 (1958) 6

9) F. P. Cranston, P. B. Snow and D. H. White, Bull. Am. Phys. Soc. 11 (1966) 909 
10) F. P. Cranston, R E Birkett and D. H. White, Bull. Am. Phys. Soc. 11 (1966) 335

11) S. Raboy and C. C. Trail, Argonne Nat. Lab. Rep. ANL-6679 (1963) 26

12) P. Spilling, H. Gruppelaar and A. M. F. Op den Kamp, Nuclear Physics A102 (1967) 209

13) J. W. Knowles, Can. J. Phys. 40 (1962) 257

14) G. van Middelkoop, Nuclear Physics A97 (1967) 209

15) R. E. Segel, E. F. Kennedy, L. L. Lee, Jr., and J. P. Schiffer, Bull. Am. Phys. Soc. 12 (1967) 92

16) T. A. Belote, A. Sperduto and W. W. Buechner, Phys. Rev. 139 (1965) B80

17) J. H. E. Mattauch, W. Thiele and A. H. Wapstra, Nuclear Physics 67 (1965) 32

18) J. P. Schiffer, Argonne Nat. Lab. Rep. ANL-6878 (1964) 279

19) B. H. Wildenthal and D. H. Youngblood, Bull. Am. Phys. Soc. 10 (1965) 377

20) R. E. Holland and F. J. Lynch, Bull. Am. Phys. Soc. 10 (1965) 1116

21) R. Bock, H. H. Duhm and R. Stock, Phys. Lett. 18 (1965) 61

22) S. M. Smith, A. M. Bernstein and M. E. Rickey, Bull. Am. Phys. Soc. 12 (1967) 93, 110

23) R. E. Coté, H. E. Jackson, Jr., L. L. Lee, Jr., and J. P. Schiffer, Phys. Rev. 135 (1964) B52

24) G. van Middelkoop and P. Spilling, Nuclear Physics 72 (1965) 1 